October 21, 2009

\title{
Gender and Generosity:
}

\section{Does Degree of Anonymity or Group Gender Composition Matter?}

\author{
C. Bram Cadsby \\ Department of Economics \\ University of Guelph \\ Guelph, Ontario, Canada \\ Maroš Servátka \\ Department of Economics and Finance \\ University of Canterbury \\ Christchurch, New Zealand
}

Fei Song

Ted Rogers School of Business Management

Ryerson University

Toronto, Ontario, Canada

\begin{abstract}
Employing a two-by-two factorial design that manipulates whether dictator groups are single or mixed-sex and whether procedures are single or double-blind, we examine gender effects in a standard dictator game. No gender effect was found in any of the experimental treatments. Moreover, neither single- versus mixed-sex groups nor level of anonymity had any impact on either male or female behavior.
\end{abstract}

Keywords: other-regarding, selfish, generous, altruism, gender, dictator, anonymity, experiment.

JEL Codes: C91, D64. 


\section{Introduction}

Numerous experimental and theoretical studies have examined and analyzed other-regarding versus self-interested behavior (e.g., Bolton and Ockenfels, 2000; Camerer, 2003; Fehr and Schmidt, 1999; Rabin, 1993). To date, extensive evidence suggests that people are not indifferent to the welfare of others, even to anonymous strangers, particularly when their choices directly determine other people's outcomes (e.g., Charness, 2000; Charness and Rabin, 2002; for an excellent recent survey on other-regarding behavior see Cooper and Kagel, 2009). A well-known and widely employed experimental framework that highlights the role of distributional otherregarding preferences is the dictator game (e.g., Forsythe et al., 1994; Kahneman, et al., 1986). In this game, one of the two parties is randomly assigned to be the "dictator" and endowed with a sum of money, \$X. The dictator is allowed to give the other party, the "recipient," any amount of money, $\$ Y$, where $0 \leq \mathrm{Y} \leq \mathrm{X}$, at the dictator's own choosing. The recipient makes no decision, but simply receives whatever is given to him/her. Since the recipient has no power to influence the dictator's decision, this game effectively removes any strategic motivation to behave in an apparently altruistic manner.

Within the large dictator-game literature, gender has been studied to determine whether one sex is more generous than the other. The most dramatic and impactful finding comes from Eckel and Grossman (1998) (EG hereafter). In a carefully designed study, they find that under doubleblind procedures, women give away twice as much as men (16\% versus $8 \%$ of the endowment). This result, which supports the conventional wisdom that women are more generous than men, has received much attention from both economists and other social scientists and has been cited widely since its publication. ${ }^{1}$ In contrast, Bolton and Katok (1995) (BK hereafter) find no gender effects ( $12 \%$ versus $11 \%$ of the endowment for women and men respectively). ${ }^{2}$ Other studies

\footnotetext{
${ }^{1}$ According to the Web of Science, Eckel and Grossman (1998) has been cited 96 times in published articles. Google Scholar lists 289 citations in published and unpublished work.

${ }^{2}$ According to the Web of Science, Bolton and Katok (1995) has been cited 41 times in published articles. Google Scholar lists 107 citations in published and unpublished work.
} 
also provide mixed and ambiguous results (e.g. Andreoni and Vesterlund, 2001; Cox, 2002; Cox and Deck, 2006; Ben-Ner, et al., 2004; Dufwenberg and Muren, 2006; Song et al., 2004), though the experimental settings in these papers are somewhat different from the standard dictator-game setting used in EG and BK. Two recent survey articles summarize the large and growing literature on gender differences in economic behavior (Croson and Gneezy, 2009; Eckel and Grossman, 2008).

A closer look at EG and BK reveals that there are notable methodological differences between these two papers. Specifically, while EG used single-sex groups in its dictator sessions and adopted a double-blind procedure, BK used mixed-sex dictator groups and a single-blind procedure. Thus, it is unclear whether the source of the different gender results was the singleversus mixed-gender dictator groups, the single- versus double-blind procedures, or some other factor. In this study, we intended to identify the source of this discrepancy by means of a two-bytwo factorial design that manipulates whether dictator groups are single or mixed-sex (henceforth $s s$ or $m s$ ) and whether procedures are single- or double-blind (henceforth $s b$ or $d b){ }^{3}$ In light of the results, we ultimately chose to run three of the four treatments that make up the complete factorial design: $s s-s b, m s-s b$, and $s s-d b$.

EG themselves stressed the importance of their double-blind setting, arguing that it "removes risk, the possibility of gender-related subject interactions, and the experimenter effect" (p. 732). We conjectured that sitting in a room in which all other decision-makers were of the same gender might also have important effects through gender priming. There is a large psychological literature on gender priming. For example, Shih et al. (1999) demonstrate that Asian-American women perform better on a mathematics test when their ethnic identity is activated and worse when their gender identity is activated than a control group. They argue that the activation of cultural and gender stereotypes is responsible for these results. In Shih et al. (1999), the priming

\footnotetext{
${ }^{3}$ For a discussion on the importance of anonymity and different experimental procedures, see Hoffman et al. (1994) and Hoffman et al. (1996).
} 
occurs through questionnaires that ask either gender- or ethnic-related questions. We hypothesized that sitting in a room with others, who are all of the same gender, might have a similar effect, especially as this is not likely to occur through random chance.

To our surprise, no gender effect was found in any of the experimental treatments. Moreover, neither single- versus mixed-sex groups nor level of anonymity had any impact on either male or female behavior.

\section{Experimental Design and Procedures}

Twenty four experimental sessions took place at the University of Canterbury in New Zealand in 2009 with 764 undergraduate students serving as subjects. The recruited dictators, but not the recipients, had never previously participated in an economics experiment. Dictator sessions and recipient sessions were run separately. The recipients were recruited for sessions which took place after the dictator sessions in a different classroom. This was done to ensure that the dictators and recipients did not run into each other on the way to the experimental sessions. Each experimental session lasted about 30 minutes including the initial instruction period and the payment of subjects. The subjects earned on average 15 New Zealand Dollars (NZD), part of which was a 5 NZD show-up fee. ${ }^{4}$

At the beginning of a session, upon entering the classroom, subjects were free to choose any seat. Each subject was provided with a copy of the instructions, which were identical for all subjects in the session. The instructions were then read aloud by the male experimenter who was the only non-subject person present in the classroom. Subjects were informed that the size of the pie was 20 NZD and dictators were instructed that they could choose one of six options from

\footnotetext{
${ }^{4}$ The adult minimum wage in New Zealand at the time of the experiment was 12 NZD per hour.
} 
giving 0 to 10 NZD to the recipient in 2 NZD increments. ${ }^{5}$ The instructions were also projected on a screen. Any questions were asked and answered privately.

In the two $s b$ treatments, the experimenter distributed decision sheets to dictators along with large manila envelopes. Once the dictator made a decision by circling one of the six available options, s/he was asked to place the decision sheet in the envelope provided to keep his/her decision private. Then the dictators were asked one by one to approach the payment desk outside the classroom where they were privately paid their experiment earnings plus the show-up fee. In the $m s-s b$ treatment, the experimenter noted the dictator's gender on a separate sheet of paper which was not visible to the subject being paid. In the recipient sessions, the large manila envelopes were placed in a box. The recipients were asked to approach the payment desk one-byone, and to draw a manila envelope from the box. They were then paid according to the decision indicated on the decision sheet inside the envelope.

In the $s s-d b$ treatment, the dictators were asked to go one by one to a private decision room to make their decision in complete privacy. On the way to the decision room, each dictator was given a small envelope containing ten two-dollar coins and a large manila envelope. ${ }^{6}$ The subjects were instructed to take out between five and ten two-dollar coins (thus having six options) and place them in their wallets, pockets, purses etc., leaving the rest for an anonymously paired recipient. They were then asked to put the small envelope in a larger manila envelope and place it in the box outside the decision room. This procedure ensured that neither the experimenter nor anybody else learned what decisions were made by individual subjects. All subjects received a show-up fee after they exited the decision room. As the $d b$ sessions were either all-male or all-female, there was no need to note the gender of the dictators. In the recipient sessions, the large manila envelopes containing small envelopes with the two-dollar

\footnotetext{
${ }^{5}$ In EG, subjects were endowed with $\$ 10$ US and chose from 11 options in $\$ 1$ increments. In BK, subjects were also endowed with $\$ 10$ US, but chose from six options comparable to those in our design.

${ }^{6}$ We could not implement the ingenious design used by EG, following Hoffman et al. (1994), because neither \$1 nor $\$ 2$ bills are used in New Zealand.
} 
coins (if any) were placed in a box as in the $s b$ sessions. The recipients were asked to approach the payment desk one-by-one and to draw a manila envelope from the box. It was stressed by the experimenter that recipients could not touch more than one envelope when making their selection. This was to avoid having subjects choose envelopes based on their weight. Once the recipients selected an envelope, they kept the two-dollar coins (if any) that were in the small envelope and received a show-up fee.

\section{Results}

Table 1 summarizes the experimental results. Panel A shows the average amount of money given away by dictators and the sample size in each of the six categories. Panel B provides the distribution of dictators' decisions in each treatment by men and women.

\section{Insert Table 1 about here}

As summarized in Table 2, using Mann-Whitney ranking tests and parametric two-sample t-tests, no gender difference was found in any of the three treatments. Moreover, using a binary measure of whether a dictator gave away a positive amount or not as the dependent variable and gender as the independent variable, logit regressions did not yield any significant gender effect in any of these three treatments either.

\section{Insert Table 2 about here}

Next, we examined whether gender-priming influenced the other-regarding behavior of men or women. Adopting the same statistical procedures as above, we did not find any significant differences for either men or women between the $s s$ and $m s$ treatments. Similarly, we examined whether our manipulation of anonymity had any impact on other-regarding behavior for either men or women, and found no significant effects. 
Given that no treatment effects were found, we pooled the data from all three treatments together to allow for greater statistical power for the gender effect analysis. The average amount given away was $\$ 3.08(15 \%)$ for men and $\$ 3.57(18 \%)$ for women. A parametric t-test of the hypothesis that the two averages are equal yields a two-tail $p$-value of 0.248 . A non-parametric Mann-Whitney ranking test of the hypothesis that the two distributions are the same yields a twotail $p$-value of 0.268 . Lastly, a binary logistic regression of the probability of giving away any positive amount showed that gender did not have any significant impact either, with a $p$-value of 0.387 .

\section{Discussion}

In this study, we were unable to explain the reason that EG found females to be more generous than males, while BK did not. Instead, our results seem to support the BK finding, even in the $s s-d b$ treatment that most resembles the EG study. Of course, there are differences between our study and that of EG. We use New Zealand university undergraduates rather than American undergraduates. Owing to the non-existence of low-denomination paper currency in New Zealand, we implement the double-blind treatment in a different manner. Following BK, we do not permit our dictators to give away more than half of their endowments. However, attitudes toward gender in New Zealand appear to resemble those in the United States, our $d b$ treatment provides complete anonymity, and in EG, only one subject, a male, gave away more than half of his endowment. Cooper and Kagel (2009) note that "results from dictator games are sensitive to a variety of seemingly innocuous variations" (p. 29). However, if the finding that women are more generous than men depends on such design features, it is difficult to maintain that it represents "a baseline difference in men and women" as EG concluded (p. 733). While this conclusion seemed appropriate and warranted given the results of their well-designed study, good science requires replication and robustness checks. Inability to replicate demands reconsideration of earlier 
conclusions. This is particularly important when the conclusion feeds into a common popular stereotype and has made such a deep impression, evidenced by the number of citations EG has received.

After completing this paper, we became aware of a related study by Boschini et al. (2009). Like us, they explore the role played by different experimental settings of the dictator game in eliciting apparent gender differences in generosity. They also examine gender priming, doing so in two ways: first, they ask subjects to specify their gender either on the first or last page of a questionnaire; second, some sessions are single-sex, while others are mixed-sex. Only an administrator, who was not otherwise involved in the experiment, observed the earnings of the subjects. They found women to be more generous than men only in their gender-first, mixed-sex treatment. Since EG used single-sex groups and did not prime their subjects by means of a questionnaire, these results, while interesting and provocative, cannot explain the differences between EG and BK.

The lesson in all this is that the jury is still out on gender differences in generosity. More evidence and replication is required before we can confidently distinguish between a corroborated conclusion and either type-1 or type-2 statistical error. 


\section{References:}

Andreoni, J., and Vesterlund, L. 2001. Which is the fair sex? Gender differences in altruism. Quarterly Journal of Economics, 116, 293-312.

Ben-Ner, A., Kong, F., and Putterman, L. 2004. Share and share alike: Gender-pairing, personality, and cognitive ability as determinants of giving. Journal of Economic Psychology, 25, 581-589.

Bolton, G., and Katok, E. 1995. An experimental test for gender differences in beneficent behavior. Economic Letters, 48, 287-292.

Bolton, G. and Ockenfels, A. 2000. ERC: A theory of equity, reciprocity, and competition. American Economic Review, 90(1), 166-193.

Boschini, A., Muren, A., and Persson, M. 2009. Constructing gender in the economics lab. Working Paper.

Camerer, C.F. 2003. Behavioral game theory: Experiments on strategic interaction. Princeton, NJ: Princeton University Press.

Charness, G. 2000. Responsibility and effort in an experimental labor market. Journal of Economic Behavior and Organization, 42, 375-384.

Charness, G., and Rabin, M. 2002. Understanding social preferences with simple tests. Quarterly Journal of Economics, 117, 817-869.

Cooper, D.J. and Kagel, J.H. 2009. Other Regarding Preferences: A Selective Survey of Experimental Results. Working paper.

Cox, J.C. 2002. Trust, Reciprocity, and Other-Regarding Preferences: Groups vs. Individuals and Males vs. Females, in Rami Zwick and Amnon Rapoport, (eds.), Experimental Business Research, Kluwer Academic Publishers. 
Cox, J.C., and Deck, C. 2006. When are women more generous than men? Economic Inquiry, 44, 587-598.

Croson, R., and Gneezy, U. 2009. Gender differences in preferences. Journal of Economic Literature, 47, 1-27.

Dufwenberg, M., and Muren, A. 2006. Generosity, anonymity, gender. Journal of Economic Behavior and Organization, 61, 42-49.

Eckel, E., and Grossman, P. 2008. Differences in the economic decisions of men and women: Experimental evidence. In C. Plott and V. Smith (eds.), Handbook of Experimental Economics Results. New York: Elsevier.

Eckel, E., and Grossman, P. 1998. Are women less selfish than men? Evidence from dictator experiments. Economic Journal, 108, 726-735.

Fehr, E., and Schmidt, K. 1999. A theory of fairness, competition, and cooperation. Quarterly Journal of Economics, 114, 817-868.

Forsythe, R., Horowitz, J., Savin, N. E., and Sefton, M. 1994. Fairness in simple bargaining experiments. Games and Economic Behavior, 6, 347-369.

Hoffman, E., McCabe, K., Shachat, K., and Smith, V. 1994. Preference, property rights and anonymity in bargaining games. Games and Economics Behavior, 7, 346-380.

Hoffman, E., McCabe, K., and Smith, V. 1996. Social Distance and Other-Regarding Behavior in Dictator Games. American Economic Review, 3, 653-660.

Kahneman, D., Knetsch, J. L., and Thaler, R. H. 1986. Fairness and the assumptions of economics. Journal of Business, 59, 285-300. 
Rabin, M. 1993. Incorporating fairness into game theory and economics. American Economic Review, 83, 1281-1302.

Shih, M., Pittinsky, T., and Ambady, N. 1999. Stereotype susceptibility: Identity salience and shifts in quantitative performance. Psychological Science, 10, 80-83.

Song, F., Cadsby, C. B., and Morris, T. 2004. Other-regarding behavior and behavioral forecasts: Females versus males as individuals and group representatives. International Journal of Conflict Management, 15, 340-363. 
Table 1. Experiment Summary

Panel A: Average Amount of Money Given Away by Dictators

Men

Double blind, single sex

Single blind, mixed sex

Single blind, single sex

All treatments

$$
\begin{aligned}
& 3.2982(\mathrm{n}=57) \\
& 2.9355(\mathrm{n}=62) \\
& 3.0344(\mathrm{n}=58) \\
& 3.08(\mathrm{n}=177)
\end{aligned}
$$

Women

$3.5600(\mathrm{n}=59)$

$3.4545(\mathrm{n}=55)$

$3.6949(\mathrm{n}=59)$

$3.57(n=173)$

Panel B: Distribution of Amounts Given Away by Dictators (Percentage in Parentheses)

Double-blind

Single-sex
Single-blind

Single-sex
Mixed-sex

$\begin{array}{ccccccc}\text { Level } & \text { Men } & \text { Women } & \text { Men } & \text { Women } & \text { Men } & \text { Women } \\ \$ 0 & 21(37 \%) & 24(41 \%) & 32(55 \%) & 29(49 \%) & 36(58 \%) & 26(47 \%) \\ \$ 2 & 12(21 \%) & 9(15 \%) & 4(7 \%) & 5(8 \%) & 3(5 \%) & 6(11 \%) \\ \$ 4 & 9(16 \%) & 7(12 \%) & 2(3 \%) & 5(8 \%) & 5(8 \%) & 6(11 \%) \\ \$ 6 & 3(5 \%) & 6(10 \%) & 8(14 \%) & 3(5 \%) & 6(10 \%) & 1(2 \%) \\ \$ 8 & 5(9 \%) & 1(2 \%) & 4(7 \%) & 0(0 \%) & 0(0 \%) & 6(11 \%) \\ \$ 10 & 7(12 \%) & 12(20 \%) & 8(14 \%) & 17(29 \%) & 12(19 \%) & 10(18 \%) \\ \text { Total } & 57(100 \%) & 59(100 \%) & 58(100 \%) & 59(100 \%) & 62(100 \%) & 55(100 \%)\end{array}$




\section{Table 2}

Gender and Treatment Hypothesis Tests ( $p$-values in parentheses)

\begin{tabular}{|c|c|c|c|}
\hline \multirow[t]{2}{*}{ Treatment } & Nonparametric & Parametric T-Test & Binary Logit Regress \\
\hline & \multicolumn{2}{|c|}{ Mann-Whitney Test } & Positive Amount Give \\
\hline \multicolumn{4}{|c|}{ Panel A: Gender Effects } \\
\hline$d b-s s$ & $0.774(0.439)$ & $0.378(0.706)$ & $0.162(0.672)$ \\
\hline$s b-m s$ & $0.900(0.368)$ & $0.697(0.487)$ & $0.435(0.244)$ \\
\hline$s b-s s$ & $0.152(0.879)$ & $0.866(0.388)$ & $0.242(0.515)$ \\
\hline$s b-m s \& s s$ (pooled) & $1.248(0.212)$ & $1.120(0.264)$ & $0.198(0.713)$ \\
\hline All treatments & $1.107(0.268)$ & $1.156(0.248)$ & $0.185(0.387)$ \\
\hline
\end{tabular}

Panel B: Gender Priming Treatment Effect

sS vs. $m s$ treatments

$0.840(0.401)$

$0.491(0.624)$

$0.301(0.186)$

Panel C: Anonymity Treatment Effect 


\section{Appendix: Experimental Materials}

\section{Experiment Instructions - Double-Blind Procedure}

\section{Instructions for Players A}

Thank you for coming. Each of you will receive a $\$ 5$ show-up fee, to be paid in cash at the end of the session. You will now have a chance to earn additional money.

The purpose of this session is to study how people make decisions in a particular situation. From now until the end of the session, unauthorized communication of any nature with other participants is prohibited. If you violate this rule we will have to exclude you from the experiment and from all payments. If you have a question, please raise your hand and we will come to you to answer your question privately.

During the session you will participate in a game that gives you the opportunity to earn money. The game concerns two players, Player A and Player B. In the game, Player A chooses one of the six available options. Each player then receives the payment specified in the chosen option. Thus, the option Player A chooses will determine his/her payment as well as that of the player B he/she is matched with. The game is played only once. Here are the 6 options.

If A chooses "Option 1," then A receives $\$ 20.00$ and B receives $\$ 0.00$. If A chooses "Option 2," then A receives $\$ 18.00$ and B receives $\$ 2.00$. If A chooses "Option 3," then A receives $\$ 16.00$ and B receives $\$ 4.00$. If A chooses "Option 4," then A receives $\$ 14.00$ and B receives $\$ 6.00$. If A chooses "Option 5," then A receives $\$ 12.00$ and B receives $\$ 8.00$. If A chooses "Option 6," then A receives $\$ 10.00$ and B receives $\$ 10.00$.

Every participant has been assigned randomly to a role. Everyone in this room is a Player A. Each of you in this room will be randomly paired with a Player B in another room. You will not be paired with anyone in this room during the experiment. This experiment is structured so that no one, neither the experimenters nor the other subjects nor anyone else will ever know the personal decision or earnings of anyone in the experiment. This is accomplished by the following procedure.

As a Player A, you will be given a small envelope with ten $\$ 2$ coins. Then, one at a time, you will go to a decision room, which is just down the hallway. Once there you are asked to make your decision in complete privacy. You will take out as many of the $\$ 2$ coins as you wish to keep and put them away. You will leave the $\$ 2$ coins that you want to give to Player B in the small envelope. Then you will put the small envelope in a manila envelope which will be provided in the decision room, and place it in the box outside the decision room. This procedure ensures that neither the experimenter nor anybody else learns your decision.

After you have made your choice, you will be privately paid a $\$ 5$ show-up fee. You will also keep your earnings from the game. Each Player B will see the choice of the Player A he/she has been matched with. Each Player B will then be paid a $\$ 5$ show-up fee plus his or her earnings from the game. Once you have been paid you are free to leave. Thank you for participating. Are there any questions? 


\section{Instructions for Players B}

Thank you for coming. Each of you will receive a $\$ 5$ show-up fee, to be paid in cash at the end of the session. You will now have a chance to earn additional money.

The purpose of this session is to study how people make decisions in a particular situation. From now until the end of the session, unauthorized communication of any nature with other participants is prohibited. If you violate this rule we will have to exclude you from the experiment and from all payments. If you have a question, please raise your hand and we will come to you to answer your question privately.

During the session you will participate in a game that gives you the opportunity to earn money. The game concerns two players, Player A and Player B. In the game, Player A chooses one of the six available options. Each player then receives the payment specified in the chosen option. Thus, the option Player A chooses will determine his/her payment as well as that of the player B he/she is matched with. The game is played only once. Here are the 6 options.

If A chooses "Option 1," then A receives $\$ 20.00$ and B receives $\$ 0.00$. If A chooses "Option 2," then A receives $\$ 18.00$ and B receives $\$ 2.00$. If A chooses "Option 3," then A receives $\$ 16.00$ and $B$ receives $\$ 4.00$. If A chooses "Option 4," then A receives $\$ 14.00$ and B receives $\$ 6.00$. If A chooses "Option 5," then A receives $\$ 12.00$ and B receives $\$ 8.00$. If A chooses "Option 6," then A receives $\$ 10.00$ and B receives $\$ 10.00$.

Every participant has been assigned randomly to a role. Everyone in this room is a Player B. Each of you in this room will be randomly paired with a Player A in another room. You will not be paired with anyone in this room during the experiment.

Players A were given a small envelope with ten $\$ 2$ coins. They could take out as many of the $\$ 2$ coins as they wished to keep and left the $\$ 2$ coins that they wanted to give to Player B in the small envelope. These small envelopes were put in a manila envelope to make them indistinguishable. As a Player B, you will see the choice of your randomly matched Player A.

We will ask each of you to go one at a time to draw a manila envelope with Player A's decision inside. After you have selected an envelope, please proceed to the payment desk just outside the room. You will then be privately paid a $\$ 5$ show-up fee plus your earnings from the game. Once you have been paid you are free to leave. Thank you for participating. Are there any questions? 


\section{Experiment Instructions - Single-Blind Procedure}

\section{Instructions for Players A}

Thank you for coming. Each of you will receive a $\$ 5$ show-up fee, to be paid in cash at the end of the session. You will now have a chance to earn additional money.

The purpose of this session is to study how people make decisions in a particular situation. From now until the end of the session, unauthorized communication of any nature with other participants is prohibited. If you violate this rule we will have to exclude you from the experiment and from all payments. If you have a question, please raise your hand and we will come to you to answer your question privately.

During the session you will participate in a game that gives you the opportunity to earn money. Immediately upon completion of the session we will pay you your total game earnings in cash. Earnings are confidential: only you and the experimenter will know the amount of money you make.

The game concerns two players, Player A and Player B. In the game, Player A chooses one of the six available options. Each player then receives the payment specified in the chosen option. Thus, the option Player A chooses will determine his/her payment as well as that of the player B he/she is matched with. The game is played only once. Here are the 6 options.

If A chooses "Option 1," then A receives $\$ 20.00$ and B receives $\$ 0.00$. If A chooses "Option 2," then A receives $\$ 18.00$ and B receives $\$ 2.00$. If A chooses "Option 3," then A receives $\$ 16.00$ and B receives $\$ 4.00$. If A chooses "Option 4," then A receives $\$ 14.00$ and B receives $\$ 6.00$. If A chooses "Option 5," then A receives $\$ 12.00$ and B receives $\$ 8.00$. If A chooses "Option 6," then A receives $\$ 10.00$ and B receives $\$ 10.00$.

Every participant has been assigned randomly to a role. Everyone in this room is a Player A. Each of you in this room will be randomly paired with a Player B in another room. You will not be paired with anyone in this room during the experiment. You will not know your partner's identity, nor will they know yours. Furthermore, these identities will not be revealed after the session is completed.

As a Player A, you will be given a Decision Form. Please indicate the option you wish to choose by circling it on the decision form. After you have made your choice, you will be privately paid a $\$ 5$ show-up fee plus your earnings from the game. Each Player B will see the choice of the Player A he/she has been matched with. Each Player B will then be paid a $\$ 5$ show-up fee plus his or her earnings from the game.

When you are finished please wait quietly. We will ask each of you to go one at a time to the payment desk just outside the room where you will be paid privately. Once you have been paid you are free to leave. Thank you for participating. Are there any questions? 


\section{Instructions for Players B}

Thank you for coming. Each of you will receive a $\$ 5$ show-up fee, to be paid in cash at the end of the session. You will now have a chance to earn additional money.

The purpose of this session is to study how people make decisions in a particular situation. From now until the end of the session, unauthorized communication of any nature with other participants is prohibited. If you violate this rule we will have to exclude you from the experiment and from all payments. If you have a question, please raise your hand and we will come to you to answer your question privately.

During the session you will participate in a game that gives you the opportunity to earn money. Immediately upon completion of the session we will pay you your total game earnings in cash. Earnings are confidential: only you and the experimenter will know the amount of money you make.

The game concerns two players, Player A and Player B. In the game, Player A chooses one of the six available options. Each player then receives the payment specified in the chosen option. Thus, the option Player A chooses will determine his/her payment as well as that of the player B he/she is matched with. The game is played only once. Here are the 6 options.

If A chooses "Option 1," then A receives $\$ 20.00$ and $\mathrm{B}$ receives $\$ 0.00$. If A chooses "Option 2," then A receives $\$ 18.00$ and B receives $\$ 2.00$. If A chooses "Option 3," then A receives $\$ 16.00$ and B receives $\$ 4.00$. If A chooses "Option 4," then A receives $\$ 14.00$ and B receives $\$ 6.00$. If A chooses "Option 5," then A receives $\$ 12.00$ and B receives $\$ 8.00$. If A chooses "Option 6," then A receives $\$ 10.00$ and B receives $\$ 10.00$.

Every participant has been assigned randomly to a role. Everyone in this room is a Player B. Each of you in this room will be randomly paired with a Player A in another room. You will not be paired with anyone in this room during the experiment. You will not know your partner's identity, nor will they know yours. Furthermore, these identities will not be revealed after the session is completed.

Players A were given a Decision Form. After a Player A had indicated his/her choice on the form, the experimenter paid him/her a $\$ 5$ show-up fee plus his/her earnings from the game. As a Player $\mathrm{B}$, you will see the choice of your randomly matched Player A.

We will ask each of you to go one at a time to draw an envelope with Player A's decision inside. After you have selected an envelope, please proceed to the payment desk just outside the room where you will open the envelope. You will then be privately paid a $\$ 5$ show-up fee plus your earnings from the game. Once you have been paid you are free to leave. Thank you for participating. Are there any questions? 


\section{Decision Form}

\begin{tabular}{|c|c|c|}
\hline Option & $\begin{array}{c}\text { Player A's } \\
\text { Earnings }\end{array}$ & $\begin{array}{c}\text { Player B's } \\
\text { Earnings }\end{array}$ \\
\hline Option 1 & $\$ 20$ & $\$ 0$ \\
\hline Option 2 & $\$ 18$ & $\$ 2$ \\
\hline Option 3 & $\$ 16$ & $\$ 4$ \\
\hline Option 4 & $\$ 14$ & $\$ 6$ \\
\hline Option 5 & $\$ 12$ & $\$ 8$ \\
\hline Option 6 & $\$ 10$ & $\$ 10$ \\
\hline
\end{tabular}

As a Player A, I choose (Please circle only one):

$\begin{array}{llllll}\text { Option } 1 & \text { Option } 2 & \text { Option } 3 & \text { Option } 4 & \text { Option } 5 & \text { Option } 6\end{array}$ 